\title{
Outcome of Surgically Treated Acute Traumatic Epidural Hematomas Based on the Glasgow Coma Scale
}

\author{
Aurélien Ndoumbe ${ }^{1^{*}}$, Martine Virginie Patience Ekeme1, \\ Chantal Simeu ${ }^{2}$, Samuel Takongmo ${ }^{3,4}$
}

${ }^{1}$ Faculty of Medicine \& Pharmaceutical Sciences, University of Douala, Douala, Cameroon

${ }^{2}$ Service of Anesthesiology \& Intensive Care, University Hospital Center of Yaoundé, Yaoundé, Cameroon

${ }^{3}$ Faculty of Medicine \& Biomedical Sciences, University of Yaoundé I, Yaoundé, Cameroon

${ }^{4}$ Service of Surgery, University Hospital Center of Yaoundé, Yaoundé, Cameroon

Email: *aurelien.ndoumbe@gmail.com, *aurelen@yahoo.fr

How to cite this paper: Ndoumbe, A., Ekeme, M.V.P., Simeu, C. and Takongmo, S. (2018) Outcome of Surgically Treated Acute Traumatic Epidural Hematomas Based on the Glasgow Coma Scale. Open Journal of Modern Neurosurgery, 8, 109118.

https://doi.org/10.4236/ojmn.2018.81009

Received: December 4, 2017

Accepted: January 21, 2018

Published: January 24, 2018

Copyright $\odot 2018$ by authors and Scientific Research Publishing Inc. This work is licensed under the Creative Commons Attribution International License (CC BY 4.0).

http://creativecommons.org/licenses/by/4.0/

(c) (i) Open Access

\begin{abstract}
This study was a retrospective analysis of outcome of surgically treated acute traumatic epidural hematomas based on the Glasgow coma scale. The series enrolled forty-six consecutive cases of acute traumatic epidural hematomas. The mean age of patients was 29.56 years and $63.04 \%$ of the patients were between 21 and 30 years of age. Forty-tree out of 46 (93.47\%) of the patients were males. Road traffic crash was the main mode of injury. The severity of the traumatic brain injury was classified according to the Glasgow coma scale score at admission. The injury was mild or moderate in 35 (76.08\%) cases and severe in 11. Eight patients (17.39\%) presented with pupillary abnormalities. The computed tomography scanning of the head has objectivized the epidural hematoma in all patients and has shown a mass effect with midline shift in all but one case (45/46). The most frequent surgical procedure done was craniotomy. Six (13.04\%) patients died (GOS 1), but 38 (82.60\%) recovered fully (GOS 5) and two (04.34\%) were disabled but independent (GOS 4). The Glasgow coma score at admission was very predictive for good or poor outcome, since all patients but one who died and all survivors who were disabled were comatose at admission ( $\mathrm{GCS} \leq 8)$.
\end{abstract}

\section{Keywords}

Traumatic Brain Injury, Epidural Hematoma, Glasgow Coma Scale, Surgery, Outcome 


\section{Introduction}

An acute traumatic epidural hematoma (ATEDH) is part of traumatic brain injury (TBI) which is a worldwide health problem with huge socio-economic impact [1]. If treated promptly and efficiently, the outcome of ATEDH is favorable in most cases. But, if left untreated, death can occur very fast. EDH is a neurosurgical emergency for which many prognostic factors have been determined [1]-[12]. One of the most important predictors for poor outcome of patients with TBI is the presence of a mass lesion requiring surgical removal as it was the case for all patients of this surgical series [12]. Factors such as the (initial) Glasgow coma scale (GCS) score or pupillary abnormalities are unanimously admitted while others such as, hematoma volume or thickness or patient age, are diversely appreciated [1]-[12]. The Glasgow coma scale was defined in 1974 by Bryan JENNETT and Graham TEASDALE in order to standardize the assessment of patients with consciousness impairment [13]. The GCS is based on patient's response to verbal order or painful stimulus on 3 items: eye opening (E), verbal $(\mathrm{V})$ and motor $(\mathrm{M})$ responses (Table 1). The GCS scores range from 3 (minimum) to 15 (maximum).The GCS has been used in various neurological pathologies which can cause consciousness impairment such as traumatic brain injury, stroke, subarachnoid hemorrhage, central nervous system (CNS) infections or CNS pathologies with raised intracranial pressure. Initially, Teasdale and Jennett defined coma as a GCS score $\leq 7$, but nowadays, coma is defined as a GCS $<9$. According to the GCS, TBI is classified in three categories: Mild TBI (GCS 13 - 15), moderate TBI (GCS 9 - 12) and severe TBI (GCS $\leq$ 8). Nevertheless, the GCS has some limitations and inappropriately assesses the level of consciousness in patients less than 5 years of age, patients with aphasia, tetraplegia or dementia. Nonetheless, the initial GCS score after resuscitation or prior to surgery, of patients with acute traumatic EDH is the strongest prognostic indicator for outcome [11]. The mortality of EDH patients with mild TBI treated surgically is near zero while that of patients with severe TBI remains significant even with prompt surgical removal [1]-[12]. Usually, outcome of patients with acute brain insults such as TBI or SAH is evaluated using the Glasgow outcome score (GOS) [2], the extended GOS, and the Rankin or modified Rankin scales. The GOS was the scale used for outcome assessment in the present series. The goal of this study was to report on the outcome of surgically treated acute traumatic epidural hematoma based on the GCS score.

\section{Patients and Methods}

Forty-six consecutive cases of ATEDHs treated at the University Hospital Center of Yaoundé, Cameroon, were retrospectively reviewed in order to assess outcome based on the GCS. The initial GCS score was determined on admission at the emergency department after resuscitation. The GCS was used for determining the severity of the TBI. The TBI was classified as mild (GCS, 13 -15), moderate (GCS, 9 - 12) or severe (GCS $\leq 8$ ), based on the GCS score at admission. 
The patients were further divided in non-comatose (GCS, 9 - 15) and comatose $($ GCS $\leq 8)$ groups. Any further neurologic deterioration also was checked. The primary end points were mortality and morbidity in relation with the GCS at admission. The influence of the GCS on focal neurologic deficits, pupillary abnormalities or neurovegetative disturbances also was studied. All patients underwent surgical removal of their ATEDH. Post-operative mortality and morbidity were analyzed in relation with the GCS score before surgery. The Glasgow outcome scale (GOS) was used to evaluate patient outcome and was determined at discharge from the hospital and after six months (Table 1). GOS of 5 and 4 (good recovery and moderate disability with independency) were considered as good outcome while scores from 1 to 3 (death, persistent vegetative state, severe disability with dependency) were considered as poor outcome.

Non traumatic EDHs, traumatic EDHs treated conservatively and EDHs with incomplete medical records were excluded from the series.

The mortality and morbidity were evaluated for mild, moderate and severe TBI groups and significant statistical differences between these groups were checked. The Fisher and Chi-square tests were used for statistical analysis and a p-value $<0.05$ with a $95 \%$ confident interval was considered as statistically significant.

\section{Results}

\subsection{Sociodemographic Data}

Forty-six patients comprising 43 (93.48\%) males and 3 females were involved in

Table 1. The Glasgow coma scale \& the Glasgow outcome score [13] [2].

\begin{tabular}{lll}
\hline & \multicolumn{2}{c}{ GLASGOW COMA SCALE [13] } \\
\hline \multicolumn{1}{c}{ Eye Opening (E) } & \multicolumn{1}{c}{ Verbal Response (V) } & \multicolumn{1}{c}{ Motor Response (M) } \\
\hline $4=$ opens spontaneously & $5=$ normal conversation & 6 =normal, obeys to command \\
$3=$ opens to voice & $4=$ confused, disoriented & $5=$ localizes pain \\
$2=$ opens to pain & $3=$ incoherent, inappropriate & $4=$ withdraws from pain \\
$1=$ none & $2=$ incomprehensible & $3=$ decorticate posturing \\
& $1=$ none & $2=$ decerebrate posturing \\
& & $1=$ none
\end{tabular}

Score $=E+V+M$. Minimum $=3$. Maximum $=15$

\section{GLASGOW OUTCOME SCORE [2]}

\begin{tabular}{cc}
\hline Score & Definition \\
\hline 1 & Dead \\
2 & Permanent vegetative state \\
3 & Severe disability, dependent \\
4 & Moderate disability, independent \\
5 & Good recovery \\
\hline
\end{tabular}


this series. Their mean age was $29.56 \pm 7.69$ years (range, 11 to 60 years). Twentynine $(63.04 \%)$ patients were in their third decade. The most frequent mode of injury was road traffic crashes (70\% of cases).

\subsection{Clinical Data}

According to the GCS score at admission, the TBI was mild in 21 (45.65\%), moderate in 14 (30.43\%) and severe in 11 (23.91\%) cases respectively. Therefore, $35(76.08 \%)$ out of 46 patients had mild to moderate TBI (GCS 9 - 15) and were classified as non-comatose, while11 patients were comatose (GCS $\leq 8$ ). Eight (17.39\%) patients presented with pupillary abnormalities, three of them were in the non-comatose group and five were in the comatose group. Nine patients had focal neurologic signs others than pupillary anomalies. Twenty-six (56.52\%) patients presented with signs of brainstem dysfunction (neurovegetative disturbances) and it was related to the GCS at admission. The hematoma volume also correlated with the GCS score at admission. No patient in the comatose group and only one patient in the non-comatose group had an EDH volume $<30 \mathrm{ml}$. Almost two-third $(63.63 \%, 7 / 11)$ of patients in coma at admission had hematoma volume $\geq 90 \mathrm{ml}$ compared to only five out of 35 (14.28\%) patients in the non-comatose group (Table 2).

\subsection{Radiological Data}

The EDH was objectivized in all patients by a brain CT scanner. All hematomas were supratentorial and the frontal-parietal location was the most frequent. Mass effect with midline shift was present in all but one case $(97.82 \%)$ with subfalcine herniation in $18(40 \%)$ of them. All patients but one had associated craniocerebral injuries such as acute subdural hematomas, skull base fractures, intracerebral

Table 2. The relationship between the GCS on admission and some clinical variables.

\begin{tabular}{|c|c|c|c|c|}
\hline GCS & $\begin{array}{l}\text { Pupillary } \\
\text { anomalies }\end{array}$ & $\begin{array}{c}\text { Focal neurologic } \\
\text { signs }\end{array}$ & $\begin{array}{l}\text { Brainstem } \\
\text { dysfunction }\end{array}$ & Hematoma volume \\
\hline & & & & Mean: $68.13 \mathrm{ml}$ \\
\hline \multirow[t]{3}{*}{$13-15(\mathrm{~N}=21 ; 45.65 \%)$} & $3(14.28 \%)$ & $4(19.04 \%)$ & $9(42.85 \%)$ & Median: $61.5 \mathrm{ml}$ \\
\hline & & & & Range: 24 - 99 ml \\
\hline & & & & Mean: $53.67 \mathrm{ml}$ \\
\hline \multirow[t]{3}{*}{$9-12(\mathrm{~N}=14 ; 30.43 \%)$} & $0(0 \%)$ & $2(14.28 \%)$ & $6(42.85 \%)$ & Median: $48 \mathrm{ml}$ \\
\hline & & & & Range: $30-66 \mathrm{ml}$ \\
\hline & & & & Mean: $84.99 \mathrm{ml}$ \\
\hline \multirow[t]{2}{*}{$3-8(\mathrm{~N}=11 ; 23.91 \%)$} & $5(45.45 \%)$ & $3(27.27 \%)$ & $11(100 \%)$ & Median: $82.5 \mathrm{ml}$ \\
\hline & & & & Range: 30 - $135 \mathrm{ml}$ \\
\hline TOTAL & 8 & 9 & 26 & \\
\hline
\end{tabular}

GCS: Glasgow coma scale. Differences between comatose (GCS $\leq 8$ ) and non-comatose (GCS > 9): pupillary anomalies, $45.45 \%$ vs $8.57 \%$; focal neurologic signs, $27.27 \%$ vs $17.14 \%$; brainstem dysfunction, $100 \%$ vs 42.85\%; hematoma volume, mean $84.99 \mathrm{ml}$, median $82.5 \mathrm{ml}$, range $30-135 \mathrm{ml}$ vs mean $62.21 \mathrm{ml}$, median $61.5 \mathrm{ml}$, range 24 - $99 \mathrm{ml} . \mathrm{P}<0.001$. 
hematoma or hemorrhagic contusions.

\subsection{Outcome}

Six (13.04\%) patients died (GOS 1$)$, two (04.35\%) had a moderate disability but were independent (GOS 4$)$, while 38 (82.61\%) had a good recovery (GOS 5) (Table 3 \& Table 4, Figures 1-3). Globally, the outcome was good (GOS, 4 - 5) for $40(86.95 \%)$ patients and poor (GOS, 1 - 3) for six (13.04\%) patients. There were no post-operative complications. All patients but one, who died were comatose (GCS $\leq 8)$, representing $83.33 \%$ (5/6) of deaths, while non-comatose patients (GCS 9 - 15) represented only $16.67 \%$ (1/6) of deaths. The mortality was $45.45 \%$ (5/11) for comatose patients as compared to $2.85 \%$ (1/35) for non-comatose ones. The persisting morbidity was $33.33 \%(2 / 6)$ in comatose survivors and nil $(0 / 34)$ in non-comatose survivors (Table 3$)$. Comatose survivors represented $100 \%$ of patients who had a post-operative disability. There were no survivors with a disability among non-comatose patients. Table 4 shows the clinical profile of the patients who died.

Table 3. Mortality, permanent disability and good recovery in relation with the GCS.

\begin{tabular}{|c|c|c|c|}
\hline \multicolumn{4}{|c|}{ MORTALITY } \\
\hline TBI type & Deceased & Survivors & Total \\
\hline Mild (GCS: 13 - 15) & $1(04.76 \%)$ & $20(95.24 \%)$ & $21(45.65 \%)$ \\
\hline Moderate (GCS: 9 - 12) & $0(00.00 \%)$ & $14(100 \%)$ & $14(30.43 \%)$ \\
\hline Severe (GCS: 3 - 8) & $5(45.45 \%)$ & $06(54.54 \%)$ & $11(23.91 \%)$ \\
\hline TOTAL & $6(13.04 \% *)$ & $40\left(86.96 \%{ }^{5}\right)$ & $46(100 \%)$ \\
\hline \multicolumn{4}{|c|}{ PERMANENT DISABILITY IN SURVIVORS } \\
\hline TBI type & Disability & No disability & TOTAL \\
\hline Mild (GCS 13 - 15) & $0(0 \%)$ & $20(100 \%)$ & 20 \\
\hline Moderate (GCS 9 - 12) & $0(0 \%)$ & $14(100 \%)$ & 14 \\
\hline Severe (GCS 3 - 8) & $2(33.33 \%)$ & $4(66.66 \%)$ & 05 \\
\hline TOTAL & $2(5 \%)$ & $38(95 \%)$ & 40 \\
\hline \multicolumn{4}{|c|}{ GOOD RECOVERY (GOS 5) IN SURVIVORS } \\
\hline TBI type & Number of survivors & Good recovery & TOTAL \\
\hline Mild (GCS 13 - 15) & 20 & $20(100 \%)$ & 20 \\
\hline Moderate (GCS 9 - 12) & 14 & $14(100)$ & 14 \\
\hline Severe (GCS 3 - 8) & 06 & $04(66.66 \%)$ & 06 \\
\hline TOTAL & 40 & $38\left(95 \%^{\dagger}\right)$ & 40 \\
\hline
\end{tabular}

Global percentage of permanent disability of the series: $04.35 \%$. There was no permanent disability in non-comatose survivors. Global percentage of good recovery (GOS $=5$ ) of the series: $82.61 \%$. The percentage of good recovery for non-comatose survivors was significantly higher than in comatose survivors $(\mathrm{P}<0.001){ }^{*}$ : global mortality of the series. ${ }^{\S}$ : global percentage of survivors. ${ }^{\dagger}$ : percentage of good recovery in all survivors of the series. TBI: traumatic brain injury.GCS: Glasgow coma scale. GOS: Glasgow outcome score. 
Table 4. The clinical profile of dead patients.

\begin{tabular}{|c|c|c|c|c|c|c|}
\hline Patient ranking & 11 & 12 & 13 & 14 & 16 & 18 \\
\hline Age (years) & 27 & 30 & 30 & 30 & 30 & 24 \\
\hline GCS & 5 & 7 & 13 & 7 & 8 & 6 \\
\hline $\mathrm{EDH}$ volume & $90 \mathrm{ml}$ & $90 \mathrm{ml}$ & $75 \mathrm{ml}$ & $105 \mathrm{ml}$ & $30 \mathrm{ml}$ & $60 \mathrm{ml}$ \\
\hline Pupillary reactivity & normal & mydriasis & normal & Mydriasis ${ }^{*}$ & normal & mydriasis \\
\hline Neurovegetative disturbances ${ }^{\S}$ & yes & yes & yes & yes & yes & yes \\
\hline ICHT & yes & yes & yes & yes & yes & yes \\
\hline Associated intracranial lesions & $\mathrm{CC}, \mathrm{PNC} \mathrm{SBF}$ & SBF & No & $\mathrm{CC}$ & $\mathrm{ICH}, \mathrm{CC}$ & ASDH \\
\hline Trauma-surgery interval (hours) & 48 & 72 & 24 & 24 & 120 & 96 \\
\hline Midline shift $>5 \mathrm{~mm}$ & yes & yes & yes & yes & yes & yes \\
\hline Subfalcine herniation & yes & yes & no & yes & yes & yes \\
\hline Extracranial injury & no & no & no & no & no & yes $^{\dagger}$ \\
\hline
\end{tabular}

EDH location

Frontal-parietal Temporal-parietal Temporal-occipital Frontal-temporal Parietal-occipital Temporal-parietal

Pyramidal signs

no

yes

no

no

no

no

GCS: Glasgow Coma Scale. EDH: epidural hematoma. ICTH: (clinical signs of) intracranial hypertension. CC: cerebral/cerebellar contusion. PNC: pneumocephalus. SBF: skull base fracture. ICH: intracerebral hematoma. ASDH: acute subdural hematoma. ${ }^{*}$ : bilateral. ${ }^{\S}$ : heart rate, blood pressure, breathing or temperature abnormalities. ${ }^{\dagger}$ : blunt abdominal trauma with intraperitoneal hemorrhage.

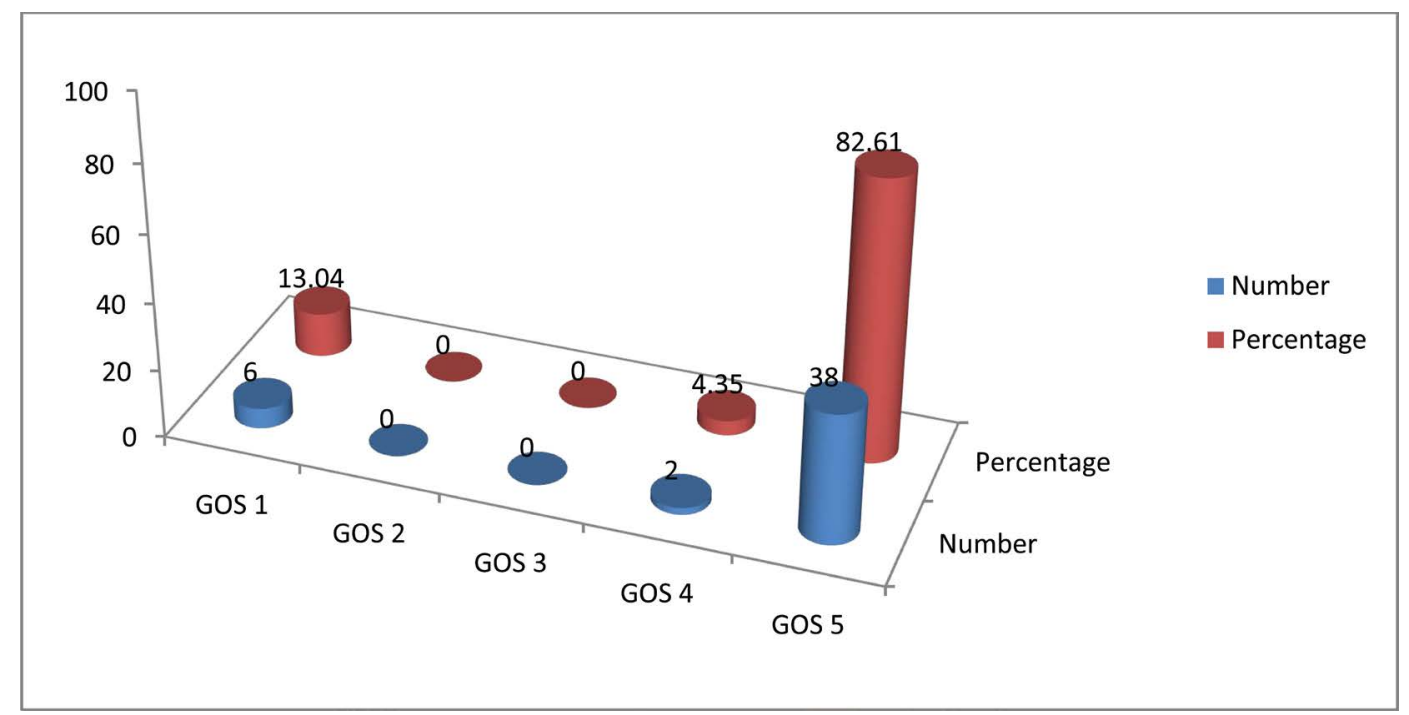

GOS: Glasgow outcome score. GOS 1, dead. GOS 2, permanent vegetative state. GOS 3, severe disability, dependent. GOS 4, moderate disability, independent. GOS 5, good recovery.

Figure 1. Global outcome.

\section{Discussion}

The presence of a mass lesion requiring surgical removal is one of the most important factors for poor outcome [11]. This was the case for any patient of the present series, since all of them needed an emergency surgical removal of their ATEDHs. Many factors determining the outcome of patients with TBI in general and acute traumatic EDH in particular have been identified. They include but 


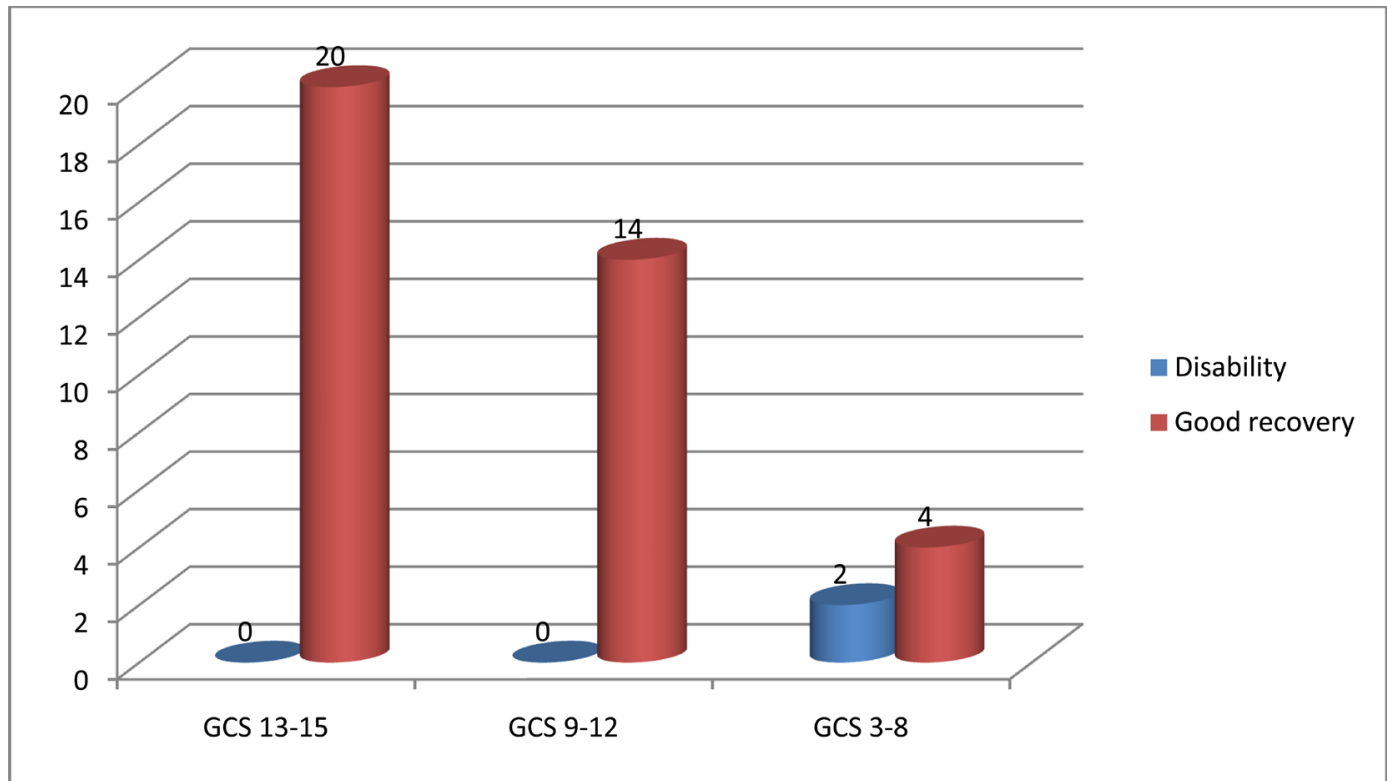

Figure 2. Functional outcome.

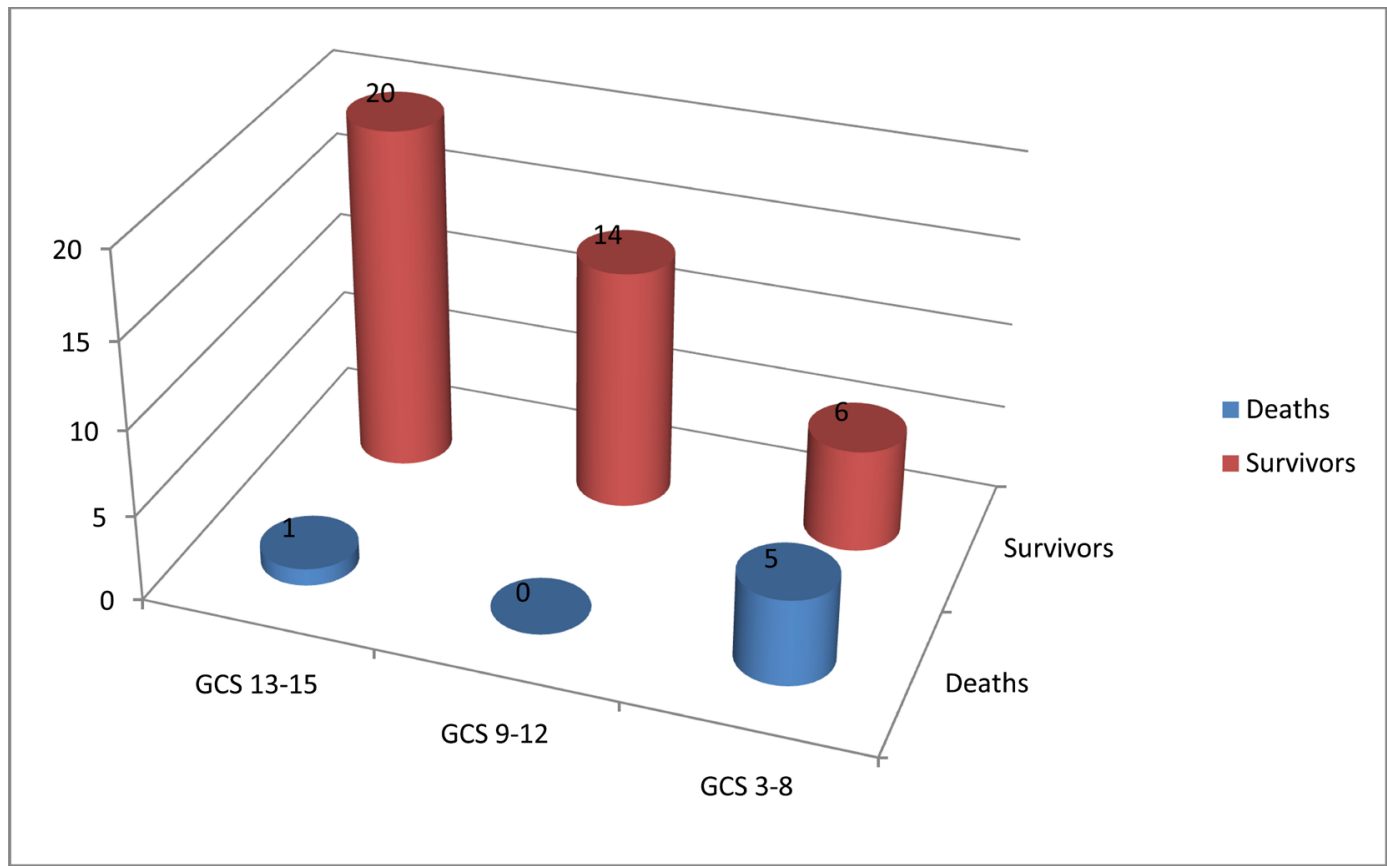

Figure 3. Fatal outcome.

are not limited to: preoperative neurologic status i.e. preoperative GCS score/ motor score, delay between trauma and operation, presence of pupillary anomalies, associated intradural injuries, hematoma size or location, age, mass effect with midline shift, and mechanism of injury and so on [1]-[12]. Some are admitted while others are still debated. Review of prognostic factors determining the outcome of ATEDHs is beyond the scope of this article. The GCS is the only factor which will be discussed here.

The global outcome of this series was as follows: mortality 6/46 (13.04\%); 
morbidity (permanent disability) 2/46 (04.34\%) and good recovery 38/46 (82.61\%) cases respectively. But, the 40 (86.95\%) patients who survived had a good outcome (GOS, 4 - 5) with only two of them having a moderate permanent disability with independency. The mortality and good outcome percentages reported in this series are consistent with data from literature in the CT era [3] [4] [5] [7] [9] [10], though some series mixed cases operated with cases treated conservatively.

The GCS at admission was strongly predictive for good or poor outcome. The mortality of patients in coma $(45.45 \%)$ was significantly higher than the global mortality of the series (13.04\%) and the mortality of non-comatose patients $(2.85 \%) \mathrm{p}<0.0001$. The chance for survival was significantly lower for comatose compared to non-comatose patients $(54.54 \%$ vs $97.14 \%) \mathrm{p}<0.001$. In the same way, the possibility for good recovery (GOS 5) was significantly lower for comatose than for non-comatose survivors (66.66\% vs $100 \%)$. Only the comatose survivors had persisting disabilities (33.33\% vs $0 \%$ ).

Kuday C et al. [7] found a strong correlation between outcome and the GCS $(p<0.00001)$. Seventy-five percent of deaths in their series occurred in comatose patients. In the series from Lobato et al. [10], mortality was restricted to patients in coma while undergoing surgery. For their 19 patients who died, 18 were comatose. Rivas et al. had reported similar findings [9]. Tataranu et al. [3] had also reported that patients in coma have a poorer outcome than patients in good neurological status, regardless of the therapy followed. Other series have shown similar results [2] [4] [5].

In their publication, Lee et al. have found significant correlation between functional outcome and preoperative consciousness state, GCS, pupillary size, motor posturing, associated brain injury, size and density of clot, importance of brain shift and obliteration of basal cisterns [6]. In the present series, there was a relationship between the GCS and prevalence of pupillary anomalies, focal neurologic signs, and brainstem dysfunction and hematoma volume. All these parameters were significantly higher in comatose than in non-comatose patients. Ropper has shown the effect of brain compression by an acute hemispheric mass such as an EDH on the level of consciousness [12].

The factors other than the GCS at admission which influenced the outcome in this series were: the hematoma size $(P=0.03)$ and midline shift with subfalcine herniation $(p=0.004)$. These two factors have a clear relationship with the level of consciousness of patients with an acute traumatic EDH.

\section{Conclusion}

The preoperative Glasgow coma scale of patients operated upon for an acute traumatic epidural hematoma was strongly predictive for outcome. Patients in coma were doomed to poor outcome while non-comatose ones were prone to good recovery. The GCS at admission had significant impact in the prevalence of mortality, persisting disability, good recovery and was correlated with the preva- 
lence of pupillary anomalies, focal neurologic signs, and brainstem dysfunction and hematoma volume. These factors were significantly different between comatose and non-comatose patients, but not between mild and moderate TBI groups.

\section{Conflict of Interest}

None.

\section{References}

[1] Ndoumbe, A., Ekeme, M.V.P., Jemea, B., Simeu, C. and Takongmo, S. (2016) Epidemiological Analysis of Surgically Treated Acute Traumatic Epidural Hematoma. Open Journal of Modern Neurosurgery, 6, 89-97. https://doi.org/10.4236/ojmn.2016.63016

[2] Jennet, B. and Bond, M. (1995) Assessment of Outcome after Severe Brain Damage. A Practical Scale. Lancet, 480-484.

[3] Tataranu, L., Ciubotaru, V., Paunescu, D., Spatariu, A. and Radoi, M. (2014) Extradural Hematoma-Is Surgery Always Mandatory? Romanian Journal of Legal Medicine, 22, 45-50. https://doi.org/10.4323/rjlm.2014.45

[4] Lal Rehman, M., Khaleeq, S. and Khaleeq, U.Z. (2010) Association of Outcome of Traumatic Extradural Hematoma with Glasgow Coma Scale and Hematoma Size. Annals of Pakistan Institute of Medical Sciences, 6, 133-138.

[5] Nazar, H., Wakeed, A. and Tariq, A. (2013) Neurosurgical Outcome of Acute Traumatic EDH Based on GCS. A.P.M.C., 7, 133-137.

[6] Lee, E.J., Hung, Y.C., Wang, L.C., Chung, K.C. and Chen, H.H. (1998) Factors Influencing the Functional Outcome of Patients with Acute Epidural Hematomas: Analysis of 200 Patients Undergoing Surgery. Journal of Trauma and Acute Care Surgery, 45, 946-52. https://doi.org/10.1097/00005373-199811000-00017

[7] Kuday, C., Uzan, M. and Hauci, M. (1994) Statistical Analysis of the Factors Affecting the Outcome of Extradural Haematoma: 115 Cases. Acta Neurochirurgica (Wien), 131, 203-6. https://doi.org/10.1007/BF01808613

[8] Cook, R.J., Donsch, N.W., Fearnside, M.R. and Chaseling, R. (1988) Outcome Prediction in Extradural Hematoma. Acta Neurochirurgica (Wien), 95, 90-94. https://doi.org/10.1007/BF01790766

[9] Rivas, J.J., Lobato, R.D., Sardia, R. and Cordobes, F. (1988) Extradural Hematoma: Analysis of Factors Influencing the Courses of 161 Patients. Neurosurgery, 23, 44-51. https://doi.org/10.1227/00006123-198807000-00010

[10] Lobato, R.D., Rivas, J.J., Cordobes, F., Alted, E., Perez, C., Sarabia, R., et al. (1988) Acute Epidural Hematoma: An Analysis of Factors Influencing the Outcome of $\mathrm{Pa}$ tients Undergoing Surgery in Coma. Journal of Neurosurgery, 68, 48-57. https://doi.org/10.3171/jns.1988.68.1.0048

[11] Stablein, D.M., Miller, J.D., Choi, S.C., et al. (1980) Statistical Methods for Determining Prognosis in severe Head Injury. Neurosurgery, 6, 243-248.

[12] Ropper, A.H. (1986) Lateral Displacement of the Brain and Level of Consciousness in Patients with an Acute Hemispheric Mass. The New England Journal of Medicine, 314, 953-8. https://doi.org/10.1056/NEJM198604103141504

[13] Teasdale, G. and Jennet, B. (1974) Assessment of Coma and Impaired Consciousness. A Practical Scale. Lancet, 2, 81-84. https://doi.org/10.1016/S0140-6736(74)91639-0 


\section{Abbreviations}

ATEDH: Acute traumatic epidural hematoma.

CNS: Central nervous system.

CT: Computed tomography.

EDH: Epidural or extradural hematoma.

GCS: Glasgow coma scale.

GOS: Glasgow outcome score.

TBI: Traumatic brain injury. 